\title{
Considering self-reported baseline function and cognition in predicting post-operative complications among older adults
}

\author{
Michelle M. Shnayder ${ }^{1}$, John R. Montgomery ${ }^{2}$, Paul Abrahamse ${ }^{3}$, Pasithorn A. Suwanabol ${ }^{2}$ \\ ${ }^{1}$ Department of Vascular and Interventional Radiology, ${ }^{2}$ Department of Surgery, ${ }^{3}$ Department of Biostatistics, University of Michigan, Ann Arbor, \\ MI, USA \\ Contributions: (I) Conception and design: PA Suwanabol; (II) Administrative support: MM Shnayder; (III) Provision of study materials or patients: PA \\ Suwanabol; (IV) Collection and assembly of data: PA Suwanabol, P Abrahamse; (V) Data analysis and interpretation: All authors; (VI) Manuscript \\ writing: All authors; (VII) Final approval of manuscript: All authors. \\ Correspondence to: Michelle M. Shnayder, MD, MPH. Department of Surgery, University of Michigan Health System, 1B407 University Hospital, \\ 1500 E Medical Center Drive, SPC 5033, USA. Email: shnayder@med.umich.edu.
}

Background: Older adults experience high rates of postoperative complications and poorer outcomes. Current perioperative risk assessments lack specific measures and are too time-consuming for busy surgeons.

Methods: Using data from the Health and Retirement Study Survey linked with Medicare data, we performed a cross-sectional study, evaluating all adults $\geq 65$ years old who underwent high-risk elective surgery between 1992-2012. Primary exposure variables included self-reported preoperative functional and cognitive abilities using activities of daily living (ADLs), instrumental activities of daily living (IADLs), and a 27-point self-administered test of memory and mental processing. Primary outcome was the development of a serious postoperative complication within 30-days following index operation.

Results: Overall, $42 \%(\mathrm{n}=501)$ developed at least one serious postoperative complication. Patients with moderate (aOR 1.52, 95\% CI: 1.14-2.04) and severe (aOR 1.55, 95\% CI: 1.00-2.46) baseline functional limitations were at higher risk of serious postoperative complications compared to those with no functional limitation. Cognitive impairment was not associated with serious postoperative complications.

Conclusions: Self-reported functional measures may help to quickly identify patients at high-risk for surgical complications and better inform pre-operative discussions including earlier initiation of palliative care services.

Keywords: Geriatric surgery; pre-surgical assessment; complications; palliative care

Submitted Mar 25, 2020. Accepted for publication Apr 22, 2020.

doi: 10.21037/apm-20-816

View this article at: http://dx.doi.org/10.21037/apm-20-816

\section{Introduction}

Older adults experience disproportionately higher rates of postoperative complications and poorer outcomes than their younger counterparts $(1,2)$. Despite efforts to promote optimal care for older patients, current perioperative risk assessments lack meaningful and specific measures, and have been cited as too time-consuming for busy surgeons (3). As such, our objective was to evaluate the association of self-reported preoperative functional and cognitive abilities with complications among older adults undergoing high- risk surgery. Such knowledge may better inform surgical decision-making and allow for earlier introductions to palliative care among this vulnerable patient population.

\section{Methods}

Using data from the Health and Retirement Study Survey linked to Centers for Medicare and Medicaid Services Part-A and B claims, we evaluated all adults $\geq 65$ years old who underwent high-risk elective surgery ( $\geq 1 \%$ inpatient mortality) between 1992-2012 (4). Primary exposure 
Table 1 Demographic data for patient's ages 65 and older who underwent high-risk surgery

\begin{tabular}{|c|c|c|c|c|}
\hline Characteristics & Total cohort, $\mathrm{N}=1,197$ & No complication, $\mathrm{N}=696$ & Complication", N=501 & $P$ value \\
\hline Male, N [\%] & $545[46]$ & $333[48]$ & $212[42]$ & 0.06 \\
\hline Race, N [\%] & & & & 0.86 \\
\hline White & $1,061[89]$ & $614[88]$ & $447[89]$ & \\
\hline Other & 27 [2] & 16 [2] & $11[2]$ & \\
\hline Elixhauser comorbidity score, mean [SD] & $0.48[1.1]$ & $0.46[1.1]$ & $0.52[1.2]$ & 0.36 \\
\hline Surgery type, $\mathrm{N}[\%]^{\dagger}$ & & & & $<0.001$ \\
\hline Cardiothoracic & $543[45]$ & 269 [37] & $274[55]$ & \\
\hline Neurological, ENT, other & $65[6]$ & $42[6]$ & $23[5]$ & \\
\hline Functional limitation ${ }^{\ddagger}$ & & & & 0.006 \\
\hline None & 825 [69] & $505[72]$ & 320 [64] & \\
\hline Mild-moderate & 271 [23] & $139[20]$ & $132[26]$ & \\
\hline Severe & $101[8]$ & $52[7]$ & 49 [10] & \\
\hline Cognitive impairment ${ }^{\S}$ & & & & 0.264 \\
\hline None & 867 [72] & 516 [74] & 351 [70] & \\
\hline Mild & 257 [21] & 142 [20] & 115 [23] & \\
\hline
\end{tabular}

\footnotetext{
${ }^{\dagger}$, high risk-surgery was defined as any operation with inpatient mortality greater than $1 \%$ (4). ${ }^{\ddagger}$, functional limitation determined by total number of ADL/IADL deficits (walking, dressing, bathing, eating, getting out of bed, and toileting) and IADLs (preparing a hot meal, shopping for groceries, making telephone calls, taking medicines, and managing money); $0=$ no limitations; $1-3=$ mild to moderate; $\geq 4=$ severe. ${ }^{\S}$, cognitive impairment determined by a 35-point self-administered test; $\geq 11=$ normal; 7-11= mild cognitive impairment; $0-6=$ severe; for patients who were unable to be interviewed, proxies were interviewed using a validated survey instrument (5). ", seriouspostoperative complications and percent [\%] of patients with each complication; deep vein thrombosis $(n=41 ; 3.4 \%)$, gastrointestinal bleed $(n=60 ; 5.0 \%)$, hemorrhage $(n=41 ; 3.4 \%)$, myocardial infarction $(n=148 ; 12.4 \%)$, pneumonia $(n=77 ; 6.4 \%)$, pulmonary failure $(n=188$; $15.7 \%)$, renal failure $(n=65 ; 5.4 \%)$, and surgical site infection $(n=53 ; 4.4 \%)$. Percent of patients with complication adds up to more than $41 \%$ because some patients had multiple complications (8). SD, standard deviation; ENT, otolaryngology.
}

variables included self-reported preoperative functional and cognitive abilities. Baseline functional status was determined by the number of activities of daily living (ADLs) and instrumental activities of daily living (IADLs) requiring assistance $(0=$ none, $1-3=$ mild-moderate, $\geq 4=$ severe functional limitations) (5). Baseline cognitive status was determined by a 27 -point scale encompassing memory, serial-7 subtractions, naming and orientation $(\geq 11=$ normal, $7-10=$ mild, $0-6=$ moderate-severe cognitive impairment) (5). Secondary exposure variables included specific ADL and IADL deficiencies. The primary outcome was development of a serious postoperative complication within 30-days following index operation identified by ICD-9 codes (Table 1, footnote).

Student's $t$-test was used to compare means and chisquare test was performed for categorical variables. Multivariable logistic regression was used to analyze outcomes with the following covariates: age, gender, comorbidity score, surgery type, functional status, cognitive status, and year of surgery (Table 1). Statistical significance 


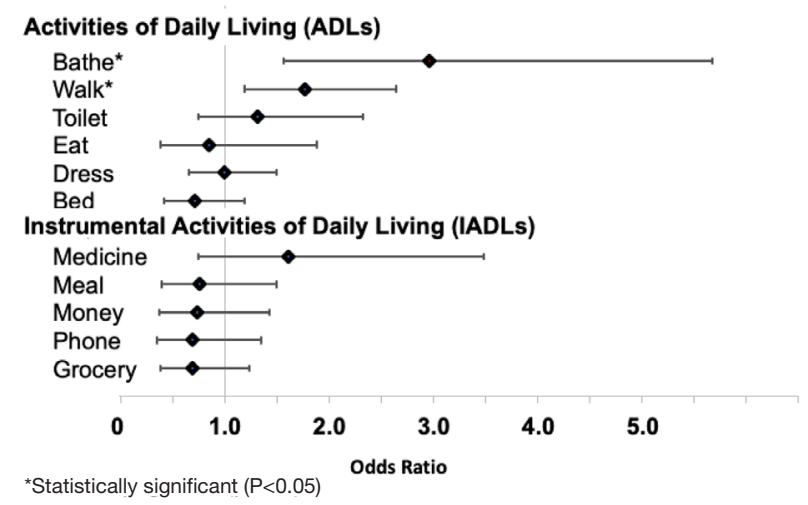

Figure 1 Adjusted $^{\dagger}$ odds of serious postoperative complications based on activities of daily living (ADLs) and instrumental activities of daily living (IADLs). ${ }^{\dagger}$, adjusting for demographics and clinical variables including age, race, gender, Elixhauser comorbidity index, surgery type, and year of surgery.

was set at $\mathrm{P}<0.05$ with two-sided tests. All analyses were performed with SAS version 9.4. This study was deemed exempt by the Michigan Medicine Institutional Review Board.

\section{Results}

Of 1,197 older adults who underwent high-risk surgery, $46 \%(\mathrm{n}=545)$ were male with a mean age of 74.7 years (SD 6.3) (Table 1). Overall, $42 \%(\mathrm{n}=501)$ developed $\geq 1$ serious postoperative complication. Among primary exposure variables, moderate (aOR 1.52, 95\% CI: 1.14-2.04) and severe (aOR 1.55, 95\% CI: 1.00-2.46) functional limitations were independently associated with serious postoperative complications compared to no functional limitation (Table 1). Cognitive impairment was not associated with serious postoperative complications. Among secondary exposure variables, the inability to bathe (aOR 3.01, 95\% CI: $1.59-5.71$ ) or walk (aOR 1.79, 95\% CI: 1.21-2.63) were independently associated with increased odds of developing serious postoperative complications (Figure 1).

\section{Discussion}

Greater baseline functional deficits are an independent predictor of serious postoperative complications among older adults undergoing high-risk elective operations. Specifically, those who demonstrate the inability to bathe or walk are at higher risk of developing complications even when adjusting for demographic and clinical factors. These simple metrics are easy to assess in busy clinical settings and may help to improve surgical decision-making and manage expectations with patients and families. Self-reported measures may also be used to rapidly identify patients who might benefit most from preoperative optimization including nutritional counseling and prehabilitation measures. Finally, as surgical patients often underutilize palliative care services, this may represent an important opportunity to introduce palliative care approaches to surgical patients whose illness trajectories may not be predictable in the immediate postoperative setting but likely demonstrate decline over the long-term $(6,7)$.

This study was limited by reliance on self-reported measures, which may lead to subjectivity, recall bias, and selection bias. Furthermore, given the data is from 1992 to 2012, it is unknown if complication rates would differ given recent advances in technology and improved surgical technique. However, our findings are drawn from a nationally representative cohort, which allows for generalizability of our results, as well as outcomes that are meaningful to patients. Importantly, our findings suggest that a brief, patient-centered approach is feasible to determine preoperative risk where quick decisions frequently have lasting consequences.

\section{Acknowledgments}

The authors wish to thank the American College of Surgeons for funding of this project.

Funding: This work is supported by the American College of Surgeons Thomas R. Russell Faculty Research Fellowship.

\section{Footnote}

Reporting Checklist: The authors have completed the STROBE reporting checklist. Available at http://dx.doi. org/10.21037/apm-20-816

Data Sharing Statement: Available at http://dx.doi. org/10.21037/apm-20-816

Conflicts of Interest: All authors have completed the ICMJE uniform disclosure form (available at http://dx.doi. org/10.21037/apm-20-816). PAS serves as an unpaid editorial board member of Annals of Palliative Medicine from May 2019 to Apr 2021. PAS reports grants from American College of Surgeons Thomas R. Russell Faculty Research 
Fellowship, from null, outside the submitted work. The other authors have no other conflicts of interest to declare.

Ethical Statement: The authors are accountable for all aspects of the work in ensuring that questions related to the accuracy or integrity of any part of the work are appropriately investigated and resolved. This study was deemed exempt by the Michigan Medicine Institutional Review Board.

Open Access Statement: This is an Open Access article distributed in accordance with the Creative Commons Attribution-NonCommercial-NoDerivs 4.0 International License (CC BY-NC-ND 4.0), which permits the noncommercial replication and distribution of the article with the strict proviso that no changes or edits are made and the original work is properly cited (including links to both the formal publication through the relevant DOI and the license). See: https://creativecommons.org/licenses/by-nc-nd/4.0/.

\section{References}

1. Min L, Hall K, Finlayson E, et al. Estimating risk of postsurgical general and geriatric complications using the VESPA preoperative tool. JAMA Surg 2017;152:1126-33.

Cite this article as: Shnayder MM, Montgomery JR, Abrahamse P, Suwanabol PA. Considering self-reported baseline function and cognition in predicting post-operative complications among older adults. Ann Palliat Med 2020;9(4):1847-1850. doi: 10.21037/apm-20-816
2. Oresanya LB, Lyons WL, Finlayson E. Preoperative assessment of the older patient: a narrative review. JAMA 2014;311:2110-20.

3. Kim SW, Han HS, Jung HW, et al. Multidimensional frailty score for the prediction of postoperative mortality risk. JAMA Surg 2014;149:633-40.

4. Schwarze ML, Barnato AE, Rathouz PJ, et al. Development of a list of high-risk operations for patients 65 years and older. JAMA Surg 2015;150:325-31.

5. Langa KM, Larson EB, Karlawish JH, et al. Trends in the prevalence and mortality of cognitive impairment in the United States: is there evidence of a compression of cognitive morbidity? Alzheimers Dement 2008;4:134-44.

6. Olmsted CL, Johnson AM, Kaboli P, et al. Use of palliative care and hospice among surgical and medical specialties in the Veterans Health Administration. JAMA Surg 2014;149:1169-75.

7. Rodriguez R, Marr L, Rajput A, et al. Utilization of palliative care consultation service by surgical services. Ann Palliat Med 2015;4:194-9.

8. Weingart SN, Iezzoni LI, Davis RB, et al. Use of administrative data to find substandard care: validation of the complications screening program. Med Care 2000;38:796-806. 